\title{
Antibacterial Potential of some Plant Extracts against Escherichia coli, along with its Phytochemical Analysis, Total Phenolic Content, and Antioxidant Properties
}

\author{
Upma Srivastava, Pooja Singh*
}

DOI: 10.18811/ijpen.v5i02.5

\begin{abstract}
In vitro antibacterial activity of 21 plant methanolic extracts were investigated by disc diffusion method against gram-negative bacteria Escherichia coli. Amongst the extracts tested, the Datura stramonium L. and Ocimum basilicum L. showed significant antibacterial activity against the bacterial pathogen. D. stramonium showed the highest antibacterial activity followed by $O$. basilicum extract. Phytochemical analysis of extracts showed the presence of alkaloids, tannins, saponins, flavonoids, and phenols. The 2,2-diphenyl-1-picrylhydrazyl (DPPH) radical scavenging and ABTS analysis of potent extract $D$. stramonium showed appreciable antioxidant activity. For DPPH and ABTS assay the highest antioxidant activity was observed at $60 \mathrm{mg} \mathrm{ml}^{-1}$ concentration with a percent inhibition of 71.66 and 77.19 with IC50 value 9.71 and $22.16 \mu \mathrm{g} \mathrm{ml}^{-1}$ respectively. Moreover, the radical scavenging activity of the extract was lower than that observed for the synthetic antioxidants butylated hydroxyanisole (BHA )and butylated hydroxytoluene (BHT). The total phenolic content of $D$. stramonium extract was found to be $0.592 \mathrm{mg}$ GAE/gm which was assayed using Folin ciocalteau reagent. The results provide evidence that the extract of $D$. stramonium and $O$. basilicum can be further recommended in the treatment of the infections caused by E. coli; further $D$. stramonium is also a potential source of natural antioxidants.
\end{abstract}

Keywords: Antibacterial, Antioxidant, Phenolic content, Plant extracts.

International Journal of Plant and Environment (2019)

\section{INTRODUCTION}

Erom antiquity, nature has been a rich store of remedies for relief From various ailments affecting mankind. Plants have been used for thousands of years in traditional medicine. The use of plants for treating diseases is as old as the human species. Plants produce a wide variety of secondary metabolites such as vitamins, terpenoids, tannins, flavonoids, alkaloids, and other metabolites, which are rich in antimicrobial and antioxidant activities (Wong et al., 2006; Baker et al., 2010). Popular observations on the use and efficacy of medicinal plants significantly contribute to the disclosure of their therapeutic properties, so that they are frequently prescribed, even if their chemical constituents are not always completely known.

Many plants have been documented for their biological (Grover et al., 2002; Gajera et al., 2005) and antimicrobial (Arora, 1998; Polambo and Semple, 2001) properties. It can be assumed, that although the bulk of traditional antibiotics can still manage drug-resistant bacteria, many commonly used antibiotics are no longer effective (Levy, 1998; Wright, 2010). Bacteria have the genetic ability to transmit and acquire resistance to drugs, which are utilized as therapeutic agents. Drug resistance can be described as a state of decreased sensitivity to drugs that ordinarily cause growth inhibition or cell death. More strains of pathogens have become antibiotic-resistant, and some have become resistant to several antibiotics and chemotherapeutic agents, the phenomenon of multidrug resistance. Limited treatment options for infections caused by such multiresistant microorganisms prompted the search for novel compounds with a broad spectrum of activity and new therapeutic strategies. To expand the spectrum of antimicrobial agents from natural resources, the plant extract was subjected to assess their antibacterial potential.

Oxygen is a highly reactive atom that is capable of becoming part of potentially damaging molecules commonly called "free
Department of Botany, DDU Gorakhpur University, Gorakhpur273009, INDIA

Corresponding Author: Dr. Pooja Singh, Department of Botany, DDU Gorakhpur University, Gorakhpur-273009, INDIA, Phone: +919415083883, Email: pooja.ddu@gmail.com.

How to cite this article: Srivastava, U. and Singh, P. (2019). Antibacterial Potential of some Plant Extracts against Escherichia coli, along with its Phytochemical Analysis, Total Phenolic Content, and Antioxidant Properties. International Journal of Plant and Environment, 5(2): 96102.

Source of support: Nil

Conflict of interest: None

Submitted:31/01/2018 Accepted:30/04/2019 Published: 30/04/2019

radicals". Free radicals are capable of attacking the healthy cells of the body, causing them to lose their structure and function. Cell damage caused by free radicals appears to be a major contributor to aging and diseases. Consequently, organisms contain a complex network of antioxidant metabolites and enzymes that work together to prevent oxidative damage to cellular components (Sies, 1997; Vertuani et al., 2004). Synthetic antioxidants such as BHA and BHT are restricted by legislative rules because they are suspected to have some toxic effects and as possible carcinogens (Feng et al.,2006). Several clinical studies are suggesting that the antioxidants in fruits, vegetables, tea, and red wine are the main actors for the observed efficacy of these foods in reducing the incidence of chronic diseases. Thus, a need for identifying alternative natural and safe sources of food antioxidants has been created, and the search for antioxidants, especially from plant origin, has notably increased in recent years. Several reports have revealed that the majority of the antioxidant activity may be from biochemicals such as flavonoids, isoflavones, flavones, anthocyanins, catechins and other phenolics (Alothman et al., 2009; Isabelle et al., 2010). 
The purpose of the present study is to investigate the antibacterial potential and antioxidant properties of plant extracts.

\section{Material and Methods}

\section{Plant materials}

The leaves 21 plants were collected from different regions of Gorakhpur district. The leaves were plucked and packed in polythene bags. Plants were initially identified by morphological features and then confirmed from the herbarium database present in the herbarium of DDU Gorakhpur University Gorakhpur. The scientific names and family of the 21 plant materials are detailed in Table 1.

\section{Preparation of plant material}

The fresh leaves were washed with tap water and then with 90 per cent alcohol, chopped into smaller pieces with a knife and then kept in the shade for 14 days to dry and then crushed using pestle and mortar and further reduced to powder using electric blender and then stored in airtight closed bottles until tested and analyzed.

\section{Extraction procedure}

$10 \mathrm{~g}$ of the powdered sample of the plant was soaked in $100 \mathrm{ml}$ of methanol in a $250 \mathrm{ml}$ conical flask at room temperature with shaking after every 4 for $24 \mathrm{~h}$. The extract was filtered using a muslin cloth and then Whatman no.1 filter paper. The filtrates were then evaporated to dryness in a rotary evaporator maintained to remove residual solvents and then stored in screw-capped bottles for further use. The extracted powder was resuspended in the methanol at desired concentrations before it was tested for the antibacterial activity.

\section{Microbial strains and preparation of inoculums}

Gram-negative bacteria Escherichia coli (MTCC No. 3053) was used for evaluation of antibacterial assay. The stock culture was maintained in nutrient agar (NA) slant at $4^{\circ} \mathrm{C}$ and sub-cultured monthly. Working cultures were prepared by inoculating a loopful of each test microorganism in $10 \mathrm{ml}$ of nutrient broth (NB) from NA slants. Broths were incubated at $37^{\circ} \mathrm{C}$ for $18-20$ hours. The suspension was diluted with sterile distilled water to obtain approximately $10^{6} \mathrm{CFU} / \mathrm{ml}$.

\section{Determination of antibacterial activity}

The antibacterial activity of plant extracts was evaluated using disc diffusion method (NCCLS, 1997). 10ml of sterilized nutrient agar medium was poured in $80 \mathrm{~mm}$ Petridishes and was allowed to solidify. The plates were seeded by spreading $0.1 \mathrm{ml}$ of overnight inoculum and allowed to set for 20-25mins. The concentration of the bacterial cultures was maintained to $10^{6}$ colony forming units (CFU)/ml using Mcfarland standard. For, screening, sterile, $6 \mathrm{~mm}$ diameter filter paper discs were soaked in plant extracts at $100 \mu \mathrm{g}$ $\mathrm{ml}^{-1}$ concentration and placed on the surface of inoculated media agar plates using sterile forceps and then gently pressed down onto the agar surface. Disk soaked with the solvent was used as control. Uninoculated plates were regarded as a negative control. This process ruled out the possibility of contamination. The positive control plates were inoculated with a test organism. All the plates were incubated at $35-37^{\circ} \mathrm{C}$ for $24 \mathrm{~h}$. Clear inhibition zones around the discs indicated the presence of antibacterial activity. Diameter of inhibition zones were measured in millimeters. An inhibition zone of $10 \mathrm{~mm}$ or more was considered as high antibacterial activity.

Table 1: Antibacterial activity of different plant extracts against the bacterial strains tested based on Disc Diffusion Method.

\begin{tabular}{|c|c|c|c|}
\hline Plant extracts & Family & Part used & Zone of inhibition \\
\hline Anisomelos indica (L.) Kuntze & Lamiaceae & Leaf & $14.33 \pm 0.46$ \\
\hline Antigonon leptopus Hook. and Arn. & Polygonaceae & Leaf & - \\
\hline Cannabis sativa $\mathrm{L}$. & Cannabaceae & Leaf & $10 \pm 0.81$ \\
\hline Catharanthus roseus (L.) G. Don & Apocynaceae & Leaf & $14 \pm 0.81$ \\
\hline Datura stramonium L. & Solanaceae & Leaf & $30 \pm 0.45$ \\
\hline Erigeron bonariensis L. & Asteraceae & Aerial parts & - \\
\hline Fleurya aestuans (L.) Gaudich. & Urticaceae & Leaf & - \\
\hline Legistromea speciosa (.L) Pers. & Lythraceae & Leaf & - \\
\hline Leonurus sibiricus L. & Lamiaceae & Aerial parts & - \\
\hline Leucas aspera Willd. & Lamiaceae & Leaf & $10 \pm 0.161$ \\
\hline Lippia alba Mill. & Verbenaceae & Leaf & $11.33 \pm 0.46$ \\
\hline Moringa olifera Lam. & Moringaceae & Leaf & - \\
\hline Ocimum basilicum $\mathrm{L}$. & Lamiaceae & Aerial parts & $16.67 \pm 0.94$ \\
\hline Ocimum gratissimum $\mathrm{L}$. & Lamiaceae & Aerial parts & - \\
\hline Ocimum sanctum $\mathrm{L}$. & Lamiaceae & Aeria; parts & - \\
\hline Oxalis corniculata L. & Oxalidaceae & Aerial parts & - \\
\hline Phyllanthus niruri L. & Phyllanthaceae & Aerial parts & - \\
\hline Putranjeeva roxburghii Wall. & Putranjivaceae & Leaf & $13.33 \pm 0.46$ \\
\hline Syzygium cumini (L.) Skeels. & Myrtaceae & Leaf & - \\
\hline Tamarindus indicus L. & Fabaceae & Leaf & - \\
\hline Tectona grandis & Lamiaceae & Leaf & - \\
\hline
\end{tabular}




\section{Determination of MIC (minimum inhibitory concentration) values}

The minimum inhibitory concentration value for bacterial pathogen was determined by agar dilution technique of CLSI with slight modifications ((NCCLS, 2002). A series of two folds dilution of extract concentrations $\left(25-3200 \mathrm{\mu g} \mathrm{ml}^{-1}\right)$ was prepared in Petridishes. $10 \mathrm{ml}$ of sterilized and molten nutrient agar medium was poured in each dish already containing $100 \mu \mathrm{l}$ amount of extracts with different concentrations. Plates were dried at $35^{\circ} \mathrm{C}$ for $30 \mathrm{~min}$ before spot inoculation with $5 \mu$ l of overnight bacterial culture (adjusted to 0.5 MacFarland standard) containing approximately $10^{5} \mathrm{CFU} /$ spot using a sterilized inoculating loop. Nutrient agar with solvent was used as positive control and similar uninoculated nutrient agar plates were kept as a negative control. The inoculum spots were allowed to dry at room temperature and plates were incubated at $35-37^{\circ} \mathrm{C}$ for $24 \mathrm{~h}$. MICs were determined as the lowest concentration of oil inhibiting the visible growth of microorganisms on agar plate disregarding the presence of 1 or 2 colonies.

\section{Determination of MBC (minimum bactericidal concentration) values}

The MBC of the extracts was determined as described by (Mishra et al., 2008). Fresh nutrient agar medium was poured into petriplates and allowed to solidify. Inoculum from various poisoned plates of MIC experiment showing no growth was submitted to subculture on freshly prepared plates. The lowest concentration of antimicrobial agent from which bacteria do not recover on the fresh medium was treated as MBC.

\section{Phytochemical analysis of extract}

To test for the presence of the active ingredients in the test sample the phytochemical analysis of extract was done according to the methods of Harborne (1978) with slight modifications.

\section{Test for alkaloids}

Each plant sample $(0.5 \mathrm{~g})$ was dissolved $2 \% \mathrm{HCl}$ in a steam bath and filtered. Three different methods were used. This mixture was allowed to cool and then filtered. The filtrate was shared in equal proportion into three test tubes and labeled A, B, C. Turbidity or precipitation was taken as evidence for the presence of alkaloids. $1 \mathrm{ml}$ of the above filtrate was treated with few drops of Mayer's reagent giving rise to a cream or pale yellow precipitate. Another 1 $\mathrm{ml}$ of filtrate was treated with a few drops of Dragendoff's reagent giving rise to a reddish-orange precipitate. Lastly, $1 \mathrm{ml}$ of filtrate was treated with Wagner's reagent giving rise to a brown or reddishbrown precipitate.

\section{Test for tannins}

About $0.5 \mathrm{~g}$ of the dried powdered samples was boiled in $20 \mathrm{~mL}$ of water in a test tube and then filtered. A few drops of $0.1 \%$ ferric chloride was added and observed for brownish green or a blueblack coloration.

\section{Test for saponin}

About $2 \mathrm{~g}$ of the powdered sample was boiled in $20 \mathrm{ml}$ of distilled water in a water bath and filtered. $10 \mathrm{ml}$ of the filtrate was mixed with $5 \mathrm{ml}$ of distilled water and shaken vigorously for a stable persistent froth. The frothing was mixed with 3 drops of olive oil and shaken vigorously, then observed for the formation of an emulsion.

\section{Test for flavonoids}

- $\quad \mathrm{NaOH}$ test: A small amount of extract was treated with aqueous $\mathrm{NaOH}$ and $\mathrm{HCl}$, observed for the formation of yellow-orange color.
- $\mathrm{H}_{2} \mathrm{SO}_{4}$ test: A fraction of extract was treated with concentrated $\mathrm{H}_{2} \mathrm{SO}_{4}$ and observed for the formation of orange colour.

- Lead acetate test: A small amount of extract was treated with lead acetate and observed for the formation of white precipitate.

\section{Test for steroids}

Two milliliters of acetic anhydride was added to $0.5 \mathrm{~g}$ ethanolic extract of each sample with $2 \mathrm{ml} \mathrm{H}_{2} \mathrm{SO}_{4}$. The color changed from violet to blue or green in the samples indicating the presence of steroids.

\section{Test for terpenoids}

Extract $(1 \mathrm{ml})$ was treated with chloroform, acetic anhydride and drops of $\mathrm{H}_{2} \mathrm{SO}_{4}$ was added and observed for the formation of dark green color.

\section{Test for phenols}

Ferric chloride test: The fraction of extract was treated with $5 \%$ ferric chloride and observed for the formation of deep blue or black color.

\section{Test for carbohydrates}

Molisch's test: Few drops of Molisch's reagent was added to each of the portion dissolved in distilled water, this was then followed by addition of $1 \mathrm{ml}$ of conc. $\mathrm{H}_{2} \mathrm{SO}_{4}$ by the side of the test tube. The mixture was then allowed to stand for two minutes and then diluted with $5 \mathrm{ml}$ of distilled water. Formation of a red or dull violet color at the interphase of the two layers was a positive test.

\section{Test for Anthraquinones}

Borntrager's test: About 50 mg of powdered extract was heated with $10 \%$ ferric chloride solution and $1 \mathrm{ml}$ concentrated $\mathrm{HCl}$. The extract was cooled, filtered and the filtrate was shaken with diethyl ether. The ether extract was further extracted with strong ammonia; pink or deep red colorations of aqueous layer indicate the presence of anthraquinone.

\section{Determination of antioxidant activity}

\section{a. DPPH free radical scavenging activity}

Effect of extracts on DPPH radical was estimated using the method of Güllüce et al. (2003) with slight modifications. 0.004\% of DPPH (Hi Media) was prepared in methanol and $2 \mathrm{ml}$ of this solution was mixed with different concentrations of extracts $(10,20,30,40,50$ and $60 \mu \mathrm{g} \mathrm{ml}^{-1}$ ) dissolved in methanol. The reaction mixture was vortexed thoroughly and left for 30 mins. After 30 mins absorbance of the mixture was measured at $517 \mathrm{~nm}$ in a UV spectrophotometer (Hitachi) against a blank (pure methanol). A control sample was also prepared as above without any oil. Ascorbic acid, BHT and BHA was taken as reference standards. Experiments were performed in triplicate and averaged. The $I C_{50}$ value was determined from percent inhibition versus concentration graph. Percent inhibition was calculated from control using the following equation:

$$
\text { Radical scavenging activity }(\%)=\frac{\left[\mathrm{Abs}_{\text {control}}-\mathrm{Abs}_{\text {sample }}\right]}{\mathrm{Abs}_{\mathrm{control}}} \times 100
$$

Where:

$\mathrm{Abs}_{\text {control }}=$ Absorbance of DPPH radical + methanol.

$\mathrm{Abs}_{\text {sample }}=$ Absorbance of DPPH radical + sample extract/standard 


\section{b. ABTS radical scavenging assay:}

For ABTS assay, the method of Adedapo et al. (2008) was adopted. The stock solutions included $7 \mathrm{mM}$ ABTS solution and $2.4 \mathrm{mM}$ potassium persulfate solution. The working solution was then prepared by mixing the two stock solutions in equal quantities and allowing them to react for $12 \mathrm{~h}$ at room temperature in the dark. The solution was then diluted by mixing $1 \mathrm{ml}$ ABTS solution with $60 \mathrm{ml}$ methanol to obtain an absorbance of $0.706 \pm 0.001$ units at $734 \mathrm{~nm}$ using the spectrophotometer. Fresh ABTS solution was prepared for each assay. $1 \mathrm{ml}$ of plant extract $(10,20,30,40,50$ and $60 \mu \mathrm{g} \mathrm{ml}^{-1}$ ) were allowed to react with $1 \mathrm{ml}$ of the ABTS solution and the absorbance was taken at $734 \mathrm{~nm}$ after 7 min using the spectrophotometer. The ABTS scavenging capacity of the extract was compared with that of $\mathrm{BHT}$ and $\mathrm{BHA}$ and percentage inhibition calculated as $A B T S$ radical scavenging activity.

$$
\% \text { inhibition }=\frac{\left[\mathrm{Abs}_{\text {control}} \mathrm{Abs}_{\text {sample }}\right]}{\mathrm{Abs}_{\text {control }}} \times 100
$$

Where:

$\mathrm{Abs}_{\text {control }}=$ Absorbance of ABTS radical + methanol

$\mathrm{Abs}_{\text {sample }}=$ Absorbance of ABTS radical + sample extract/standard

\section{c. Determination of total phenolic contents}

The total phenolic content of $D$. stramonium extract was determined according to the method of Muruhan et al. (2013) with slight modifications using Gallic acid as the standard. $1 \mathrm{ml}$ of various concentrations of $D$. stramonium $\left(100,200,300\right.$, and $400 \mu \mathrm{g} \mathrm{ml}^{-1}$ ) were mixed with $2 \mathrm{ml}$ of $7.5 \% \mathrm{Na}_{2} \mathrm{CO}_{3}$ and after $2 \mathrm{~min} 0.1 \mathrm{ml}$ of Folin Ciocalteau (Hi Media) reagent (diluted tenfold with distilled water) was added and mixed well. After 30 mins incubation, the absorbance of mixtures was recorded spectrophotometrically at $750 \mathrm{~nm}$. The total phenolic contents were calculated as gallic acid equivalent (GAE) from a calibration curve of gallic acid standard solutions and expressed as $\mathrm{mg}$ of gallic acid per gm of extract sample.

\section{Results}

\section{Antibacterial activity}

Results from antibacterial disc diffusion assay are summarized in Table 1. Some of the extracts showed moderate to high inhibiting activity while most of the extracts did not found effective against tested the tested bacterial pathogen. The zones of inhibition ranged from $10-30 \mathrm{~mm}$. Results showed that Datura stramonium and Ocimum basilicum extracts showed significant antibacterial activity against the bacteria tested. Additionally, the extracts of Anisomeles indica and Catharanthus roseus also showed moderated inhibitory activity. D. stramonium showed the highest activity forming $30 \mathrm{~mm}$ zone of inhibition against Escherichia coli followed by 0 . basilicum which formed $16.67 \mathrm{~mm}$ inhibition zone. The zone of inhibition formed by other extracts was negligible. Furthermore, the antibacterial activity of the most effective extract against $E$. coli quantitatively was assayed by determination of minimum inhibitory concentration (MIC) and minimum bactericidal concentration (MBC).

\section{Minimum inhibitory concentration (MIC) and minimum bactericidal concentration (MBC)}

$D$. stramonium exhibited strong action against $E$. coli with MIC value of $800 \mu \mathrm{g} \mathrm{ml}^{-1}$ followed by the extract $O$. basilicum with $1600 \mathrm{\mu g} \mathrm{ml}^{-1}$ MIC value (Table 2). MBC values were found to be 1600 and $3200 \mu \mathrm{g}$ $\mathrm{ml}^{-1}$ for $D$. stramonium and Ocimum basilicum respectively (Table 2 ).

\section{Phytochemical analysis}

The preliminary phytochemical screening with the various qualitative chemical tests revealed the presence of various secondary metabolites like Alkaloids, tannins, saponins, flavonoids, tannins. The results were shown in Table 3.

\section{Antioxidant activity}

During an assessment of the antibacterial potential of an extract; Datura stramonium was most potent, thus was subjected to further investigation of its antioxidant properties.

\section{DPPH radical scavenging assay}

The DPPH radical scavenging activity of the most potent extract, D. stramonium and references are shown in Figure 1.D. stramonium methanolic extract notably reduced the concentration of DPPH free radical, with an efficacy lower than that of reference $\mathrm{BHA}$ (Butylated hydroxyl anisole) and BHT (Butylated hydroxytoluene). The results showed a significant decrease in the concentration of DPPH free radical due to the scavenging ability of extract and reference. The decrease in the concentration of DPPH was observed with the increase in the concentration of extract. The highest antioxidant activity was observed at $60 \mathrm{mg} \mathrm{ml}^{-1}$ concentration (75.66\%). The IC50 value of extract was found to be $9.71 \mathrm{\mu g} \mathrm{ml}^{-1}$.

\section{ABTS radical cation decolorization assay}

The results are demonstrated in Figure 2. The results showed that

Table 2: MIC and MBC data of D. stramonium and O.basilicum extracts against $E$. coli in $\mu \mathrm{g} \mathrm{ml}^{-1}$.

\begin{tabular}{lllll}
\hline \multirow{2}{*}{ Bacterial strain } & \multicolumn{2}{c}{ D. stramonium } & \multicolumn{2}{l}{ O. basilicum } \\
\cline { 2 - 5 } & MIC & MBC & MIC & MBC \\
\hline E. coli & 800 & $\leq 1600$ & 1600 & $\leq 3200$ \\
\hline
\end{tabular}

Table 3: Results of phytochemical screening.

\begin{tabular}{lll}
\hline Test & D. stramonium & O. basilicum \\
\hline Alkaloids & & + \\
Dragendroff's Test & + & + \\
Mayers's Test & + & + \\
Hagers's Test & + & + \\
Tannins & + & + \\
Saponins & + & \\
Flavonoids & & + \\
NaOH Test & + & + \\
$\mathrm{H}_{2} \mathrm{SO}_{4}$ Test & + & + \\
Lead acetate Test & + & - \\
Steroids & - & - \\
Terpenoids & - & + \\
Phenols & + & - \\
Carbohydrates & - & - \\
Anthraquinones & - & \\
\hline
\end{tabular}


Table 4: Total phenolic content and antioxidant activity regarding to $I C_{50}$ value of plant extract.

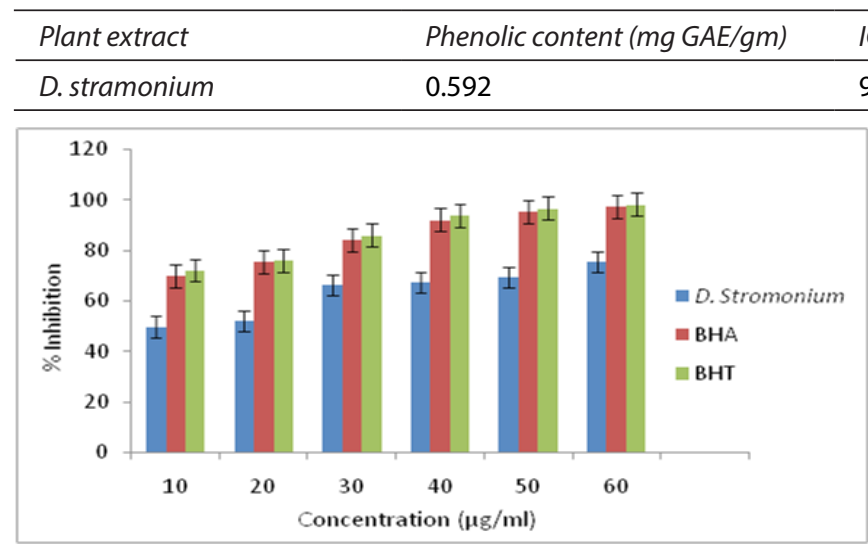

Fig. 1: Free radical scavenging activity of $D$. stramonium extract and reference antioxidants at different concentrations showing percent inhibition of DPPH radical.

Datura extract was found to be a good scavenger of ABTS free radicals. The rise in the concentration of the extract was found to enhance the radical scavenging ability. At $60 \mathrm{\mu g} \mathrm{ml}^{-1}$ concentration, the highest activity of extract was observed. Percent inhibition was $77.19 \%, 95.66 \%$ and $94.82 \%$ for Datura extract, BHA and BHT respectively. In ABTS scavenging assay the $\mathrm{IC}_{50}$ value of $D$. stramonium extract was found to be $22.16 \mathrm{\mu g} \mathrm{ml}^{-1}$.

\section{Total phenolic content}

Phenolics are the class of compounds, which acts as free radical scavengers and are responsible for the antioxidant activity in many plants. The total phenolic contents in D. stramonium was measured by Folin- Ciocalteau reagent expressed as Gallic acid equivalent (GAE) in $\mathrm{mg} \mathrm{g}^{-1}$ (standard curve equation $\mathrm{y}=0.0059 \mathrm{x}+0.0579, \mathrm{R}^{2}=$ 0.9255). The total phenolic equivalent ranged from 0.256 to 0.592 $\mathrm{mg} \mathrm{GAE} / \mathrm{gm}$ at different concentrations (Table 4). The highest total phenolic content was observed at $500 \mathrm{~g} \mathrm{ml}^{-1}$ concentration $(0.592$ mg GAE/gm).

\section{Discussion}

\section{Antibacterial activity}

Out of 22 extracts tested, only methanolic extracts of $D$. stramonium and $O$. basilicum exhibited good antibacterial activity and gave a zone of inhibition against E. coli. Eloff (1998) reported that methanol was the most effective solvent for plant extraction than any other solvents. Soniya et al. (2013) also found methanol as the most effective solvent. D. stramonium showed the highest inhibitory activity against a bacterial pathogen. The present study is comparable with the reports of Sharma and Sharma (2013) and Gachande and Khillare (2013) and Sreenivasa et al. (2012). $O$. basilicum extract was proved good in inhibiting $E$. coli after D. stramonium as reported by Hossain et al. (2010). It has been hypothesized that the inhibition involves phenolic compounds, because these compounds sensitize the phospholipid bilayer of the microbial cytoplasmic membrane causing increased permeability, unavailability of vital intracellular constituents and impairment of bacterial enzymes. Though the minimum inhibitory concentration is high, nevertheless it showed that plant extract under in-vitro study has broad antibacterial activity. Generally, it is well known that gram-negative bacteria are more resistant than gram-positive bacteria. However, in this study E. coli, a gram-negative bacteria

$I_{50}$ value in $\mu \mathrm{g} \mathrm{ml}^{-1}$ (DPPH assay) $\quad I C_{50}$ value in $\mu \mathrm{g} \mathrm{m}^{-1}$ (ABTS assay)

9.71
22.16

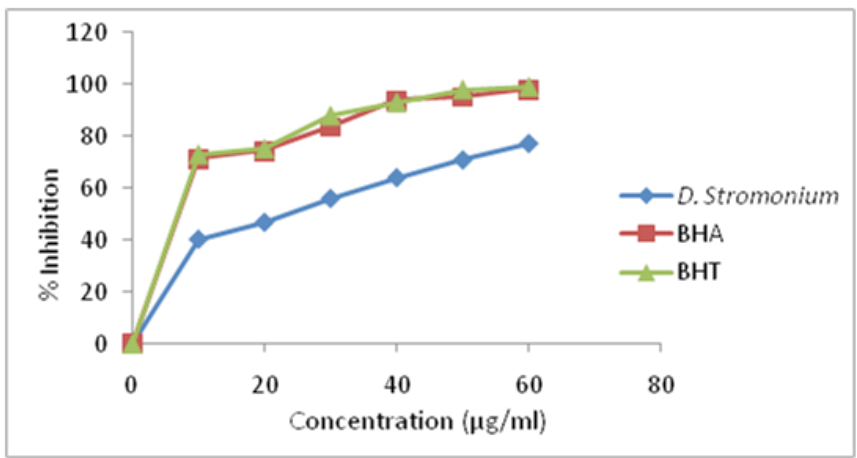

Fig. 2: Total antioxidant activity of $D$. stramonium extract and reference antioxidants by ABTS radical cation decolorization assay.

was found sensitive to the extract of $D$. stramonium followed by O. basilicum.

\section{Phytochemical analysis}

The constituents of the extracts of $D$. stramonium (dried) leaves contain compounds which may be responsible for their observed antioxidant and antibacterial activities. These are phenolic compounds, alkaloids, flavonoids, tannins, and saponins. Alkaloids have established broad-spectrum antibacterial activity and are also used as analgesics and narcotics for pain relief. This supports earlier findings which reported the anti-inflammatory action of Fagara, a known antisickling phytomedicine (Elekwa et al., 2008). Flavonoids and phenolics found in the extracts are suggestive of their antioxidant property. Phenolic compounds make up one of the major families of secondary metabolites in plants. Flavonoids enhance the effects of vitamin $C$ and function as antioxidants. They are also known to be biologically active against liver toxins, tumors, viruses, and other microbes, allergies, and inflammation. Tannins are found in almost every plant part: bark, wood, leaves, fruits, and roots (Scalbert, 1991). Many human physiological activities, such as stimulation of phagocytic cell, host-mediated tumor activity and a wide range of anti-infective actions, have been assigned to tannins (Haslam, 1996). Tannins can be toxic to filamentous fungi, yeasts, and bacteria (Scalbert, 1991). Saponins are glycosides with foaming characteristics. They are common in a large number of plants and plant products that are important in human and animal nutrition (Francis et al., 2002).

\section{Total phenolic content and antioxidant activity}

Oxygen is one of the most essential components for living, it is also a double-edged sword. Oxygen is a highly reactive atom that is capable of becoming part of potentially damaging molecules commonly called "free radicals". Cell damage caused by free radicals appears to be a major contributor to aging and diseases like cancer, heart disease, a decline in brain function, a decline in the immune system, etc. Due to the negative and toxic effects of synthetic antioxidants, natural phenolic antioxidants are being promoted as food preservatives and diet supplements (Botsoglou et al., 2002; Shetty, 1997).

DPPH is a stable free radical which accepts an electron or hydrogen radical to become a stable diamagnetic molecule, which is widely used to investigate the radical-scavenging activity. In 
DPPH radical scavenging assay, antioxidants react with $\mathrm{DPPH}$, and convert it to yellow colored $a, a$-diphenyl- $\beta$-picryl hydrazine. The degree of discoloration indicates the radical-scavenging potential of antioxidant activities (Blois, 1958). Figure 1 shows DPPH scavenging activity of $D$. stramonium extracts at different concentrations in comparison with well known synthetic antioxidants. The antioxidant activity reflected by the DPPH radical scavenging assay was observed in the methanolic leaf extract of $D$. stramonium.

The ABTS assay is based on the inhibition by antioxidants of the absorbance of radical cation ABTS, which has a characteristic long-wavelength absorption spectrum. Proton radical scavenging is an important attribute of antioxidants. ABTS, a protonated radical has characteristic absorbance maximum at $734 \mathrm{~nm}$ which decreases with the scavenging of proton radicals (Mathew and Abraham, 2006). Generation of ABTS radical cations forms the basis of one of the spectrophotometric methods that have been applied to the measurement of total antioxidant activity of various substances. Higher concentrations of the extract were more effective in quenching free radicals (Fig. 2).

In DPPH as well as ABTS assay, the inhibition was found to be concentration-dependent. Percent inhibition was found directly proportional to the concentrations of extract i.e. with the increase in concentration there is also an increase in percent inhibition. The presence of phytochemicals such as phenolic compounds, flavonoids may directly contribute to the antioxidant activity of the extract.

Many studies demonstrated a correlation between phenolic content and antioxidant activity (Yang et al., 2002). On the other hand, Bajpai et al. (2005) reported no correlation between total phenolic content and antioxidant capacities of many medicinal plant extracts. The phenolic compounds may contribute directly to the antioxidative action and are also good hydrogen donors, which makes them good antioxidants (Dudonne et al., 2009). Total phenolic content was found to be $0.592 \mathrm{mg} \mathrm{GAE} / \mathrm{gm}$. To a certain level, we can establish a correlation between total phenolic content and antioxidant activity in the present study conducted.

D. stramonium extract was found to have promising antioxidant activity as a well good antibacterial activity along with an appreciable amount of total phenolic content. The DPPH and ABTS both the assays proved that the antioxidant activity of the extract was appreciable. It can be used as a potential source of natural antioxidants.

\section{ACKNOWLedgment}

The authors are thankful to the Department of Botany, D.D.U. Gorakhpur University, Gorakhpur for providing lab facilities.

\section{References}

Adedapo, A.A., Jimoh, F.O., Koduru, S., Afolayan, A.J. and Masika, P.J. 2008. Antibacterial and antioxidant properties of the methanol extracts of the leaves and stems of Calpurnia aurea. BMC Complementary and Alternative Medicine 8(53):1-8.

Alothman, M., Bhat, P. and Karim, A.A. 2009. Antioxidant capacity and phenolic content of selected tropical fruits from Malaysia, extracted with different solvents. Food Chemistry 115:785-788.

Arora, D.S. 1998. Antimicrobial activity of tea (Camellia sinensis). Antibioics and Chemotherapy 2:4-5.

Bajpai, M., Pande, A., Tewari, S.K. and Prakash, D. 2005. Phenolic contents and antioxidant activity of some food and medicinal plants. International Journal of Food Sciences and Nutrition 56:287-291.

Baker, J.C., Owens, R.A., Whitaker, B.D., Mock, N.M., Roberts, D.P., Deahl, K.L. and Aver'yanov, A.A. 2010. Effect of viroid infection on the dynamics of phenolic metabolites in the apoplast of tomato leaves. Physiological and Molecular Plant Pathology 74:214-220.

Blois, M.S. 1958. Antioxidant determinations by the use of a stable free radical. Nature 181:1199-1200.

Botsoglou, N.A., Christaki, E., Fletouris, D.J., Florou-Paneri, P. and Spais, A.B. 2002. The effect of dietary oregano essential oil on liid oxidation in raw and cooked chicken during refrigerated storage. Meat Science 62:259-265.

Dudonne, S., Vitrac, X., Coutiere, P., Woillez, M. and Merillon J.M. 2009. Comparative study of antioxidant properties and total phenolic content of 30 plant extracts of industrial interest using DPPH, ABTS, FRAP, SOD, and ORAC assays. Journal of Agricultural and Food Chemistry 57:1768-1774.

Elekwa, I., Monanu, M.O. and Anosike, E.O. 2005. Effects of aqueous extracts of Zanthoxylum macrophylla roots on membrane stability of human erythrocytes of different genotypes. Biokemistri 17:7-12.

Eloff, J.N. 1998. Which extractant should be used for the screening and isolation of antimicrobial components from plants? Journal of Ethnopharmacology 60:1-8.

Feng, Z.Q., Ni, K.F., He, Y., Ding, Z.S., Zhu, F., Wu, L.G. and Shen, M.H. 2006. Experimental study on effect of Tetrastigma hemsleyanum Diels et Gilg flavone on inducing apoptosis of SGC-7901 cell line in vitro. Chinese Journal of Clinical Pharmacolgy and Therapeutics 11:669-672.

Francis, G., Kerem, Z., Makkar, H.P. and Becker, K. 2002. The biological action of saponins in animal systems: a review. British Journal of Nutrition 88:587-605.

Gachande, B.D. and Khillare, E.M. 2013. In-vitro evaluation of Datura species for potential antimicrobial activity. Bioscience Discovery 4:78-81.

Gajera, H.P., Patel, S.V. and Golakiya, B.A. 2005. Antioxidant properties of some therapeutically active medicinal plants: An overview. Journal of Medicinal and Aromatic Plant Sciences 27:91-100.

Grover, J.K., Yadav, S. and Vats, V. 2002. Medicinal plants of India with antidiabetic potential. Journal of Ethnopharmacology 81:81-100.

Güllüce, M., Sökmen, M., Daferera, D., Ağar, G., Ozkan, H., Kartal, N., Polissiou, M., Sökmen, A. and Sahin, F. 2003. In vitro antibacterial, antifungal, and antioxidant activities of the essential oil and methanol extracts of herbal parts and callus cultures of Satureja hortensis L. Journal of Agricultural and Food Chemistry 51:3958-3965.

Harborne, J.B. 1978. Phytochemical methods, 3rd ed, London: Chapman and Hall, London 60:135-203.

Haslam, E. 1996. Natural polyphenols (vegetable tannins) as drugs: possible modes of action. Journal of Natural Products 59:205-215.

Hossain, M.A., Kabir, M.J., Salehuddin, S.M., Rahman, S.M., Das, A.K., Singha, S.K., Alam, M.K. and Rahman, A. 2010. Antibacterial properties of essential oils and methanol extracts of sweet basil Ocimum basilicum occurring in Bangladesh. Pharmaceutical Biology 48:504-511.

Isabelle, M., Lee, B.L., Lim, M.T., Koh, M.T., Huang, D. and Nam, C. 2010. Antioxidant activity and profiles of common fruits in Singapore. Food Chemistry 123:77-84.

Levy, S.B. 1998. The challenge of antibiotics resistance. Scientific American 278:46-53.

Mathew, S. and Abraham, E.T. 2006. In vitro antioxidant activity and scavenging effects Cinnamomum verum leaf extract assayed by different methodologies. Food and Chemical Toxicology 44:198-206.

Mishra, A.K., Mishra, A., Tripathi, S. and Tripathi, N.N. 2008. Susceptibility of Enterococcus faecalis to plant volatiles oils. Journal of Microbiology World 10:108-112.

Muruhan, S., Selvaraj, S. and Viswanathan, P.K. 2013. In vitro antioxidant activities of Solanum surattense leaf extract. Asian Pacific Journal of Tropical Biomedicine 3:28-34.

NCCLS (National Committee for Clinical Laboratory Standards) 2002. Performance standards for antimicrobial disk and dilution susceptibility tests for bacteria isolated from animals.

NCCLS (National Committee for Clinical Laboratory Standards) 1997. Performance Standards for Antimicrobial Disk Susceptibility Test. Approved Standard M2-A6: Wayne PA.

Polambo, E.A. and Semple, S.J. 2001. Antibacterial activity of traditional Australian medicinal plants. Journal of Ethnopharmacology 77:151-157. 
Scalbert, A. 1991. Antimicrobial properties of tannins. Phytochemistry 30:3875-3883.

Sharma, P. and Sharma, R.A. 2013. Comparative antimicrobial activity and phytochemical analysis of Datura stramonium L. plant extracts and callus In vitro. European Journal of Medicinal Plants 3:281-287.

Shetty, K. 1997. Biotechnology to hamess the benefits of dietary phenolics: Focus on Lamiaceae. Asia Pacific Journal of Clinical Nutrition 6:162-171.

Sies, H. 1997. Oxidative stress: Oxidants and antioxidants. Experimental Physiology 82:291-295.

Soniya, M., Kuberan, T., Anitha, S. and Sankareswari, P. 2013. In vitro antibacterial activity of plant extracts against Gram positive and Gram negative pathogenic bacteria. International Journal of Microbiology and Immunology Research 2:1-5.
Sreenivasa, S., Vinay, K. and Mohan, N.R. 2012. Phytochemical analysis, antibacterial and antioxidant activity of leaf extract of Datura stramonium. International Journal of Science Research 1:83-86.

Vertuani, S., Angusti, A. and Manfredini, S. 2004. The Antioxidants and Pro-Antioxidants Network: An Overview. Current Pharmaceutical Design 10:1677-1694.

Wong, C.C., Li, H.B., Cheng, K.W. and Chen, F. 2006. A systematic survey of antioxidant activity of 30 chinese medicinal plants using the ferric reducing antioxidant power assay. Food Chemistry 97:705-711.

Wright, G.D. 2010. Antibiotic resistance in the environment: a link to the clinic?. Current Opinion in Microbiology 13:589-594.

Yang, J.H., Lin, H.C. and Mau, J.L. 2002. Antioxidant properties of several commercial mushrooms. Food Chemistry 77:229-235. 